\title{
El mérito de la "Araucana"
}

\begin{abstract}
$\mathrm{A}^{\mathrm{N}}$ NTE un grupo de hispanistas no hay que hacer la presentación de la Araucana. Ya somos amigos. Se saben los pormenores exteriores: que Ercilla acompañó al Príncipe Felipe en su viaje a Inglaterra para casarse con María Tudor; que allí oyó hablar de las noticias inquietantes del Virreinato del Perú; que se unió a las fuerzas expedicionarias y luego a la escuadra que llegó a Concepción en un momento bastante avanzado de la guerra araucana; que tomó parte en varios encuentros bélicos y en algunas exploraciones; que sacó la espada, junto con otro caballero en presencia del General Garcia Hurtado de Mendoza; que fue condenado a muerte y que el indulto no fue concedido hasta poco antes de la hora fijada nara la ejecución.

Ercilla decidió escribir un poema sobre la guerra araucana. Nos informa él mismo que compuso trozos de la obra en pedacitos de papel o cuero en momentos de descanso de las batallas. Si no nos convence enteramente de la exactitud de esta especie, podría aproximarse a la verdad en algunos cantos del poema. También existen dudas sobre el efecto que ejerciera sobre el poeta su terrible aventura con su jefe; se ha creído que por ello descuidó bastante los hechos de Don García y exaltó a los araucanos. De todos modos volvió a España en 1563. La primera parte de la Araucana (quince cantos) salió a luz en 1569, la segunda parte con otros quince cantos en 1578, y la tercera parte con siete más en 1589.
\end{abstract}

Como otras epopeyas (p. ej. el Furioso y la Gerusalemme) la Araucana ha seguido un curso tempestuoso en el mar de la 
crítica. No le han faltado ni elogiadores ni impugnadores. Sería fácil extraviarse en esta crítica y sobre todo llegar a una extensión desmesurada. En Chile el poema ha sido aceptado muchas veces como una epopeya nacional precursora del espíritu de la independencia. En España ha sido recibido por lo común como el mejor poema narrativo del Siglo de Oro, pero con algunas reservas. En otros países, incluso Francia donde se ha comentado bastante (Voltaire, Nicolas, Royer, Ducamin), la obra ha merecido mucho aprecio, mezclado con desdén. La manía del crítico extranjero, y no pocas veces del español, parece haber sido demostrar que la Araucana no alcanza el nivel artístico del Furioso, la sensibilidad de la Gerusalemme o el patriotismo artístico y completo de los Lusiadas. Este punto de vista negativo no es precisamente denigrante para don Alonso, dejándole segundo (o sea, según el caso, cuarto) en tal compañía.

El impulso de decir ahora algo más sobre el manoseado tema de la Araucana deriva de algunos juicios críticos recientes. En su original Historia personal de la literatura chilena (Santiago, 1954, pp. 31-44), citando a Solar Correa y añadiendo de lo suyo, el crítico "Alone" apunta que la España contemporánea de Ercilla halló difícil el aceptar como material digno de una epopeya lo que parecía solamente un incidente fronterizo contra un grupo insignificante de salvajes. El joven crítico Fernando Alegría, en La poesía chilena (Berkeley, 1954, p. 1), escribe: "Curiosa es la situación de don Alonso de Ercilla en la historia de la literatura española. Hasta sus críticos más acerbos no han dejado de reconocer la presencia del genio en varios aspectos de su obra. Sin embargo, cuando se leen las opiniones de los españoles ilustres sobre la Araucana no pasa inadvertido el hecho de que en ellas existe algo como una amabilidad forzada, una especie de admiración a regañadientes. Parece que la crítica española ha buscado por siglos a un poeta épico que supere a Ercilla con el objeto de evitarse el bochorno de presentar como la mejor epopeya española un poema al que los preceptistas le niegan el carácter de "epopeya", y al que los españoles mismos sienten que no les pertenece totalmente". 
Como si lo hiciera a propósito para convalidar el parecer de los dos críticos chilenos, Joaquín de Entrambasaguas saca a luz una espléndida edición de la Jerusalén Conquistada de Lope de Vega. ${ }^{1}$ Describe el intento de Lope como "la creación de un poema nacional que, en España, no poseíamos, pese a La Araucana de Ercilla, La Austríada de Rufa, o cualquier otro de estos poemas narrativos; falta más patente ya que en el vecino Portugal Os Lusiadas de Camoens representaban la consecución completa y genial de lo que los demás pueblos de Europa anhelaban" (III, 20).

Se comprende que Entrambasaguas ha intentado una atrevida rehabilitación de la Jerusalén Conquistada. Por sus vastos conocimientos de Lope de Vega y de su época se leen con respeto sus palabras. Aun discrepando de su juicio, no se trata precisamente de refutarle. Ha escrito un admirable comentario sobre la Jerusalén. Tal vez sea siempre pueril parangonar a dos poetas como si fueran atletas dispuestos a medir sus fuerzas. En cambio se trata de explicar la boga de que gozaba y de que todavía goza la Araucana. Poco importa si en algunas calidades la aventaja la Jehusalén, el Bernardo, la Cristíada.

Procuremos señalar las positivas calidades de la Araucana. En primer lugar vuelve la atención del lector hacia la gran hazaña internacional heroica y perdurable del pueblo español -el descubrimiento y la colonización de América. A un español de aquella época le habrán parecido más importantes Granada, las campañas del Gran Capitán, Pavía, Lepanto, las guerras contra Francia e Inglaterra. ¿Quién lo duda? Pero la intuición o la experiencia personal o la buena suerte de Ercilla dio en la gran aventura americana con todos sus rasgos novedosos y exóticos. Habría sido imposible incluir en una obra

1 Lope de Vega, Jerusalén Conquistada, Epopeya trágica, Edición y estudio crítico de Joaquín de Entrambasaguas, tres tomos (Madrid, 1954).

Doy por casi seguro que "Alone" y Alegría no habían visto esta edición, que salió en el mismo año que las obras de ellos. Sin embargo, es posible. En. trambasaguas había preparado la edición que se publicó en la conmemoración del tercer centenario (1935) de la muerte de Lope de Vega. Casi todos los ejemplares desaparecieton en un incendio de la guerra civil española. El editor amplió el comentario en la edición de 1954. 
todos los complicados episodios de la conquista de Indias. Resulta más poético el hecho de que Ercilla lo hizo con naturalidad, siguiendo sus propias experiencias y lo que él sabía, en lugar de un acontecimiento de primer orden, como la conquista del Perú. Tal vez tropezara Ercilla casi casualmente con su materia, tal vez acertara sin teorizar. Esto no desvirtúa la afortunada selección del tema.

Ercilla mismo es un personaje bastante importante del poema. Por sí mismo esto no constituye un mérito; más bien podría parecer un defecto, una vulgarización de la materia heroica. Es la manera como se retrata lo que gana la simpatía del lector. Es una figura humana, reflexiva, casi sentimental, con un mínimo de vanagloria. Se demora un momento con orgullo por su casa ancestral de Vizcaya; relata con gusto su maniobra traviesa para alcanzar el punto más meridional de las exploraciones; castiga al comandante que lo condenó a morir con las palabras mozo capitán acelerado (puede haber aquí para el lector moderno una leve ironía: después de todo, al sacar la espada, ¿no fue Ercilla el 'acelerado'?). Por lo común, como personaje del poema, no aparece en la plenitud de las luchas sanguinarias ni en las batallas decisivas, a pesar de haber tomado parte en ellas. Entra en escena después; comenta desfavorablemente las crueles represalias; es portavoz de la defensa de Dido contra Eneas (absurdo si se quiere) ; se encuentra con figuras sobrenaturales. En medio de la guerra, manifiesta un sentimiento humanitario.

Un extranjero cavilará mucho antes de formular un juicio sobre cuestiones de estilo poético. Se ha acusado a Ercilla de ciertas crudezas. Nadie quisiera igualarle, en la belleza de los versos, con Lope de Vega, Fray Luis de León, Fernando de Herrera. Probablemente estaba menos dotado, era menos sutil que Balbuena. Pero sabía referir un episodio heroico clara y fuertemente. Comunica eficazmente el ambiente de pelea. El lector no se acordará de los combates y las audacias de la Jerusalén y del Bernardo tan bien como de los de Lautaro, Tucapel y Rengo. iValgan algunos parangones! La epopeya debería ser sencilla, directa, descubierta como en Homero y (perdónese la comparación) Boiardo, como si se compusiera por gusto. Cuando se complica y se enreda, como lo hacían Virgi- 
lio, Ariosto, Tasso, Camoens, Balbuena, Lope de Vega, se puede embellecer notablemente, pero se pierde algo de la cadena de sucesos y de la claridad. Ercilla poseía el don de la narración sencilla, briosa y heroica, aunque a veces lo olvidaba en los episodios.

Puede carecer de lógica el alegar como mérito el espíritu de vacilación o de incertidumbre. El caso de Ercilla es extrano. Fue impulsado por su imaginación poética a relatar en octavas reales la guerra araucana. Se propuso no permitir que ningún otro elemento (amor, aventura, intriga) estorbase el progreso marcial del poema. Pero antes del fin de la primera parte insertó una situación sentimental e idílica. En la segunda y la tercera parte intercala episodios sentimentales, nacionalistas, científicos o pseudo-científicos, como si deseara compensar el rigor de guerra. No sólo introduce estos episodios ajenos, sino que comenta en las octavas mismas sus problemas estéticos. Expone al lector su alma de poeta. No sabe si adherir a la cruenta realidad de la guerra chilena o pasarse al mundo de sueños del Renacimiento. Hace las dos cosas, si bien permanece principalmente en la campaña araucana, o sea en la escuela histórica de la epopeya. Se revela como individuo complejo y, como nos gusta decir, moderno.

Desde luego el mérito más grande de la Araucana es la apreciación del enemigo. Los indios araucanos son representados, por cierto, como salvajes y brutales, pero también son patrióticos y heroicos, defensores de la libertad. Un crítico agudo (Royer) ha dicho que todos se parecen. No estoy enteramente de acuerdo. El joven Lautaro, muerto antes del fin de la primera parte, es generoso y simpático más que los otros. El jefe supremo, Caupolicán, aceptado tantas veces como el gran representante de la raza, me parece carecer un poco de personalidad, como Agamenón en la Ilíada o Carlomagno en la Chanson de Roland. Los dos que prefieren la pelea a todo, Tucapel y Rengo, representan al verdadero salvaje. El mutilado Galvarino, episódico como es, es posiblemente el más formidablemente heroico.

De todos modos esta apreciación del enemigo es el rasgo distintivo de la Araucana. Trasciende la predilección de Tasso por Solimán, la de Boiardo por Agricane, la de Homero por 
Héctor. En cuanto a nuestros épicos modernos - son éstos los corresponsales de guerra y los fotógrafos- no se atreverían a pintar así al enemigo. Probablemente perderían sus puestos. Se comprende que Chile ha adoptado la Araucana como una especie de poema nacional. En cierto sentido es más para España. Cubre su poesía narrativa de una aureola de generosidad caballerosa que se repite en otros poetas, si no a tal extremo. En el reino de la guerra y la poesía épica, si se permite la comparación, refleja algo del espíritu generoso de Bartolomé de las Casas, o si éste es una figura demasiado discutida, de Sahagún y Motolinía. Además, a pesar de las imitaciones y los ecos de Ariosto, Virgilio, Lucano, es en el conjunto una obra señaladamente original por el tema, por el ambiente, por el espíritu.

JOHN VAN HORNE, Carleton College, Northfield, Minnesota 